\section{Fibrinmonomere, lösliche}

T. Stief

Institut für Laboratoriumsmedizin und Pathobiochemie, Krankenhaus der Philipps-Universität, Marburg, Deutschland

Englischer Begriff Fibrin monomers, soluble fibrin

Definition Lösliches Fibrin ist Thrombin-gespaltenes $>$ Fibrinogen (Fibrinmonomer), das auspolymerisiert, quervernetzt wird und z. T. noch in Lösung bleibt.

Beschreibung Fibrinmonomere entstehen durch die Abspaltung des Fibrinopeptids A durch $\gg$ Thrombin oder Thrombinähnliche Proteinasen (DesAA-Fibrin). Fibrinmonomer polymerisiert zu Fibrinpolymer, das dann durch Faktor 13a quervernetzt wird. Ein kleiner Teil des gebildeten Fibrins, sogar des quervernetzten Fibrins, ist löslich und zirkuliert mit dem fließenden Blut durch den Körper.

Lösliches Fibrin bildet die Wirkung von Thrombin auf Fibrinogen ab und kann damit zum Nachweis einer gesteiger- ten Thrombinbildung eingesetzt werden. Erhöhte Konzentrationen werden demzufolge bei Thrombosen oder bei DIC (disseminierte intravasale Koagulopathie) gemessen. Funktionstests basieren beispielsweise darauf, dass lösliches Fibrin die t-PA-vermittelte Umwandlung von > Plasminogen zu Plasmin katalysiert. Arginin-Anwesenheit erhöht die Spezifität, ansonsten könnte auch Fibrinogen-Fragment X ( durch Plasmin initial gespaltenes Fibrinogen) t-PA stimulieren. Problematisch ist die Präzipitationstendenz von löslichem Fibrin, sodass erhöhte Konzentrationen möglicherweise nicht gemessen werden können, da das Fibrin auf dem Endothel auspräzipitierte.

\section{Literatur}

Stief TW (2000) Functional determination of soluble fibrin polymers (SFP) in plasma. Thromb Haemost 84:1120-1121

Wiman B, Ranby M (1986) Determination of soluble fibrin in plasma by a rapid and quantitative spectrophotometric assay. Thromb Haemost 55: $189-193$ 